\title{
Mechanical properties of experimental resin
}

\section{cements containing different photoinitiators and co-initiators}

This article was published in the following Dove Press journal: Clinical, Cosmetic and Investigational Dentistry

\author{
Carla dos Reis Lima' \\ Danilo Bandeira da Silva ${ }^{2}$ \\ Rafael Pino Vitti ${ }^{3}$ \\ Milton Edson Miranda' \\ William Cunha Brandt ${ }^{2}$ \\ 'Department of Prosthodontics, São \\ Leopoldo Mandic, Campinas I3045-54I, \\ SP, Brazil; ${ }^{2}$ Department of Implantology, \\ University of Santo Amaro, São Paulo \\ 04743-030, SP, Brazil; ${ }^{3}$ Department of \\ Dentistry, Herminio Ometto University \\ Center, Araras 13607-339, SP, Brazil
}

Correspondence: Rafael Pino Vitti Department of Dentistry, Herminio Ometto University Center, Av. Dr. Maximiliano Baruto, 500, Araras 13607-339, SP, Brazil $\mathrm{Tel} / \mathrm{Fax}+551935431400$

Email rafapvitti@gmail.com

\begin{abstract}
Aim: The aim of this study was to evaluate the influence of different concentrations of two photoinitiators and one co-initiator on the flexural strength (FS) and elastic modulus (E) of experimental resin cements.
\end{abstract}

Materials and methods: A mixture containing BisGMA, TEGDMA, and barium-aluminumsilicate $(\mathrm{BaAlSi})$ and silanized colloidal silica $\left(\mathrm{SiO}_{2}\right)$ filler particles was prepared with two photoinitiators, viz. camphorquinone (CQ) and bisacylphosphine oxide (BAPO). Dimethylaminoethyl methacrylate (DMAEMA) was used as co-initiator. Thirty groups $(n=10)$ were formulated with different photoinitiator systems (CQ/DMAEMA and BAPO/DMAEMA) and concentrations (wt $\%$ ) of photoinitiator and co-initiator. The photoactivation was carried out for $20 \mathrm{~s}$ with a light-emitting diode (LED, Bluephase, Ivoclar Vivadent) with irradiance of 1200 $\mathrm{mW} / \mathrm{cm}^{2}$. The FS and E were obtained in a three-point bending test on a universal testing machine $(0.5 \mathrm{~mm} / \mathrm{min})$. Data were subjected to the Kolmogorov-Smirnov normality test, followed by two-way ANOVA and Tukey's test ( $\alpha=0.05)$.

Results: No polymerization occurred in the CQ groups without DMAEMA (0 wt $\%$ ). DMAEMA $0.5 \%$ wt and $1 \%$ wt groups showed statistically similar FS and E results for CQ and BAPO, except for CQ $0.3 \mathrm{wt} \%$ (FS), CQ 0.9wt $\%$ (E) and BAPO $1.76 \mathrm{wt} \%$ (FS and E) for DMAEMA $0.5 \%$ wt. No significant difference was found for FS and E values for different concentrations of photoinitiators, except for CQ $0.25 \mathrm{wt} \%$ (FS and E) and BAPO $0.25 \mathrm{wt} \%$ (E) that showed the lowest values.

Conclusion: The wt $\%$ of the photoinitiators and co-initiator influenced the mechanical properties and the performance of CQ was dependent on the DMAEMA concentration. BAPO can be used as substitute for the conventional CQ/DMAEMA photoinitiator system. Keywords: mechanical properties, monomers, photoinitiators, resin cements

\section{Introduction}

The resin cements generally contain three main components: fillers (inorganic part), resin matrix (organic part), and silanization agent. ${ }^{1,2}$ The fillers are used in resin cements to provide reduction of polymerization shrinkage, reduction of coefficient of linear thermal expansion and water sorption. However, with increasing filler content, compressive, tensile, and flexural strength, elastic modulus, and wear resistance are generally increased. ${ }^{3}$ Incorporation of filler into the resin blend improves aesthetics and material handling. ${ }^{4}$

The resin matrix also has an important influence on the chemical and physicalmechanical properties of the cements. ${ }^{5}$ It consists of methacrylate monomers, such 
as bisphenol A glycidyl methacrylate (BisGMA), triethylene glycol dimethacrylate (TEGDMA), urethane dimethacrylate (UDMA), and bisphenol-A-ethoxy-dimethacrylate (BisEMA). ${ }^{6}$ Resin cements polymerization can be activated by light exposure. In this case, it becomes necessary to add a photoinitiator system to the resin matrix so as to initiate the process of free radical development and complete the polymerization reaction. ${ }^{7}$

Based on the mechanism of free radical formation after light absorption, the system can be classified as Norrish type I or II. The type I system generates radicals by fragmentation of the photoinitiator molecule, whereas in type II the excited state photoinitiators need to interact with co-initiators, electron and proton donors so that radicals can be generated. ${ }^{8}$

The photoinitiator system most commonly used in resin cements is Norrish type II which is formed by the photoinitiator camphorquinone (CQ) and an amine used as co-initiator such as dimethylaminoethyl methacrylate (DMAEMA). ${ }^{9}$ The CQ is activated by absorption of visible light between 50 and $500 \mathrm{~nm}$, causing the carbonyl group to pass from singlet to triplet state. Considering that the energy of a photon at $468 \mathrm{~nm}$ is insufficient to directly cleave a carbon-based radical initiator, the co-initiator (DMAEMA) donates hydrogen to generate polymerization of the material. ${ }^{8}$ Although this system is generally preferred, it can compromise procedures such as aesthetics restorations since the CQ is yellow in color. ${ }^{10}$ Tertiary amines tend to react with an acidic group (e.g. phosphoric acid), undesirably generating the quaternary ammonium salt or adverse interactions, thus tending to cause discoloration depending on the type and concentration of the amine in the system. ${ }^{11}$ Furthermore, the CQ and amine are identified in exudates of resin cements with cytotoxic effects. $^{6}$

Bisacylphosphine oxide (BAPO), Norrish type I photoinitiator, with part of its absorption in the visible spectrum between 365 and $416 \mathrm{~nm}$, has presented advantages such as white coloration of the compound thus aiding in the incident light penetration, and at the same time acting on increasing the polymerization depth through the resin as it has a high reactivity, and the use of amine as a co-initiator being unnecessary in this initiation system. ${ }^{12,13}$

The quality (mechanical and esthetic properties) of photoactivated resin cements is directly related to the characteristics of the polymer matrix ${ }^{3,5}$ and there are few studies that have looked at the mechanical properties of such materials with different initiators/co-initiator types and concentration, and this question needs clarification. Thus, the aim of this study was to investigate the influence of different concentrations of CQ and BAPO (initiator), and DMAEMA (co-initiator) on the flexural strength (FS) and elastic modulus (E) of experimental light-cured resin cements. The hypotheses of the study were that; (i) the CQ would promote better FS and E values than BAPO; (ii) the higher concentration of the photoinitiators would improve the FS and $\mathrm{E}$ values.

\section{Materials and methods Preparation of experimental resin cements}

The resin matrix for resin cements consisted of a combination of dimethacrylates monomers: BisGMA (50 wt $\%$; Sigma-Aldrich, St. Louis, MO, USA) and TEGDMA (50 wt $\%$; Sigma-Aldrich, St. Louis, MO, USA). The experimental resin cements were loaded with $50 \mathrm{wt} \%$ silanated $(\gamma$-methacryloxypropyl trimethoxysilane) filler: irregular 80 wt $\%$ BaAlSi particles with $1.0 \mu \mathrm{m}$ and $20 \mathrm{wt} \% \mathrm{SiO}_{2}$ with $0.04 \mu \mathrm{m}$ in size. The difference among the experimental resin cements was the photoinitiator system (CQ or BAPO) in different $w t \%$. The co-initiator agent was DMAEMA. For the prevention of spontaneous polymerization of dimethacrylates, $0.1 \mathrm{wt} \%$ BHT was added. Therefore, the following photoinitiator systems were tested:

CQ $(0.1,0.3,0.5,0.7$, or $0.9 \mathrm{wt} \%)$ and DMAEMA $(0,0.5$, or $1.0 \mathrm{wt} \%)$;

BAPO $(0.2,0.7,1.2,1.7$, or $2.2 \mathrm{wt} \%)$ and DMAEMA $(0,0.5$, or $1.0 \mathrm{wt} \%)$.

The resin cements were packed in plastic pots wrapped in an aluminum foil to protect the material from ambient light.

The photoactivation was carried out using a polywave light-emitting diode (LED, Bluephase, Ivoclar Vivadent; $\left.1200 \mathrm{~mW} / \mathrm{cm}^{2}\right)$ maintaining the distance $(10 \mathrm{~mm})$ between LED source and sample using a black cover with circular hole in the middle.

\section{Sample preparation}

Using a teflon master die, addition silicone matrices (Express, 3M ESPE, St. Paul, MN, USA) with $7.0 \mathrm{~mm}$ length, $2.0 \mathrm{~mm}$ width, and $1.0 \mathrm{~mm}$ height were made. The resin cements were inserted in a single increment using a syringe, covered with a polyester strip and a glass plate $(1.0 \mathrm{~mm})$. The photoactivation was performed for $20 \mathrm{~s}$. 
The materials were inserted into the matrices in a single increment, over which a polyester strip and a glass plate were placed to decrease the inhibition of the polymerization reaction by oxygen in the surface layer. This procedure prevents the contact of the material with air, eliminating the layer of unpolymerized resin, in addition to promote greater surface smoothness. After the polymerization, the samples were removed from the silicon matrix, their bases identified with red pilot pen and separated by groups and subgroups in individual plastic eppendorfs.

For each photoactivation, a new strip of polyester was used in order to prevent changes in light intensity. After polymerization of each group $(n=10)$, the addition silicone matrix was replaced thus preventing contamination between the experimental cements. All samples were carefully prepared in an environment with controlled temperature $\left(25 \pm 1^{\circ} \mathrm{C}\right)$ and stored for $24 \mathrm{hrs}\left(37^{\circ} \mathrm{C}\right)$.

\section{Flexural strength and elastic modulus}

The samples were separated from the mold and excess material was removed using a 1200 grit SiC paper (Norton SA, São Paulo, SP, Brazil). The dimensions of specimens were analyzed using a digital caliper (Absolute Digimatic, Mitutoyo, Tokyo, Japan) and immediately submitted to the three-point bending in universal testing machine (DL500, EMIC, São José dos Pinhais, PR, Brazil) using a span of $5 \mathrm{~mm}$ and radii of support rods of $1.2 \mathrm{~mm}$ at a crosshead speed of $0.5 \mathrm{~mm} / \mathrm{min}$ (Figures 1 and 2). During the flexural strength test, the software of the universal testing machine calculated the elastic modulus from the elastic portion of the stressstrain graph.

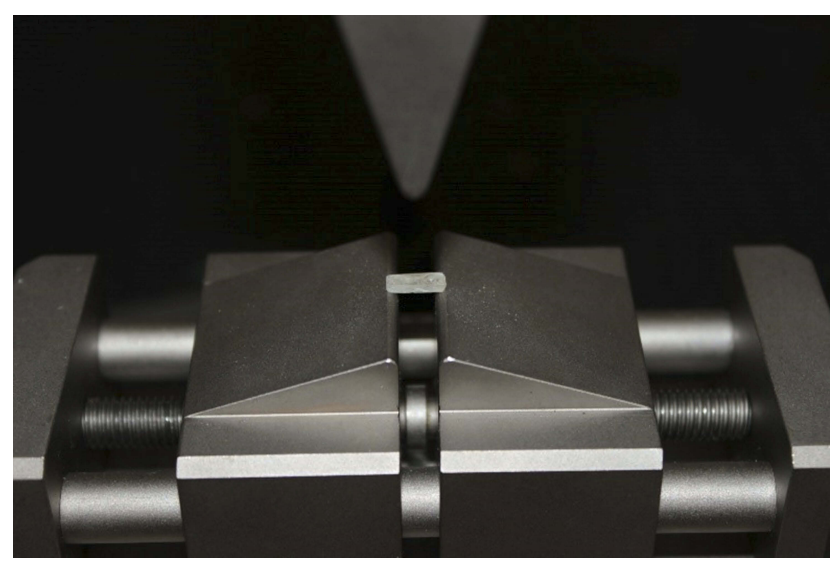

Figure I Specimens positioned on the universal testing machine.

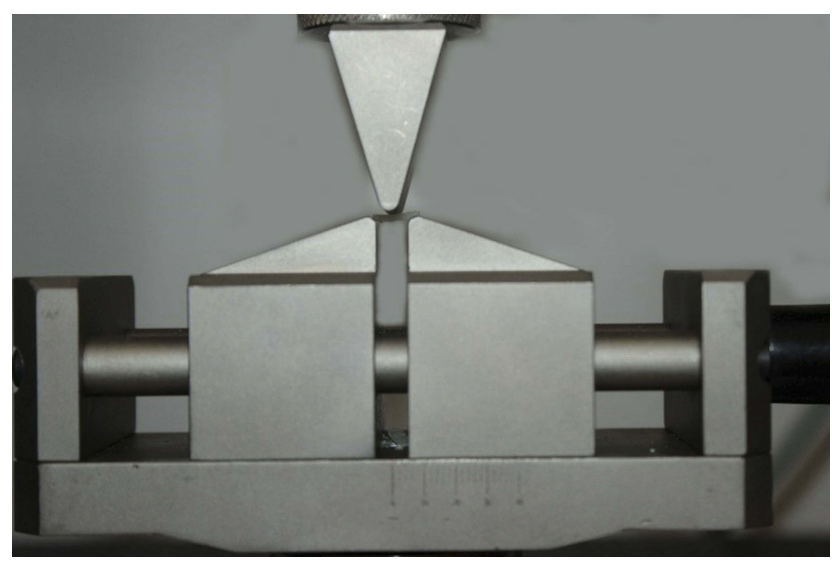

Figure 2 Force applied on the specimen.

\section{Statistical analysis}

FS and $\mathrm{E}$ distributions of the data were investigated with the Kolmogorov-Smirnov normality by test. Afterward, data were statistically evaluated using a two-way analysis of variance (ANOVA). The means were compared using Tukey's test $(\alpha=0.05)$.

\section{Results}

The FS results are presented in Table 1. The statistical analysis showed a statistically significant interaction between the factors studied $(\rho<0.001)$. Furthermore, significant effect was found for initiator $(\rho<0.001)$ and for coinitiator $(\rho<0.001)$. When the co-initiator (DMAEMA 0 ) was not used, the materials containing CQ did not polymerize, whereas those containing BAPO polymerized but did not show statistically significant differences for FS

Table I Means (standard deviations) for flexural strength (MPa) according to initiator (CQ and BAPO \%wt) and co-initiator (DMAEMA \%wt) used

\begin{tabular}{|l|l|l|l|}
\hline & DMAEMA 0 & DMAEMA 0.5 & DMAEMA I.0 \\
\hline CQ 0.I & $0.0(0.0) \mathrm{B}, \mathrm{b}$ & $66.0(13.3) \mathrm{A}, \mathrm{b}$ & $68.0(20.9) \mathrm{A}, \mathrm{c}$ \\
CQ 0.3 & $0.0(0.0) \mathrm{C}, \mathrm{b}$ & $61.4(27.0) \mathrm{B}, \mathrm{b}$ & $98.9(44 . \mathrm{I}) \mathrm{A}, \mathrm{abc}$ \\
CQ 0.5 & $0.0(0.0) \mathrm{B}, \mathrm{b}$ & $86.7(36.7) \mathrm{A}, \mathrm{ab}$ & $101.6(24.1) \mathrm{A}, \mathrm{abc}$ \\
CQ 0.7 & $0.0(0.0) \mathrm{B}, \mathrm{b}$ & $79.1(33.4) \mathrm{A}, \mathrm{ab}$ & $83.5(46.2) \mathrm{A}, \mathrm{bc}$ \\
CQ 0.9 & $0.0(0.0) \mathrm{B}, \mathrm{b}$ & $77.7(39.8) \mathrm{A}, \mathrm{ab}$ & $81.8(46.5) \mathrm{A}, \mathrm{bc}$ \\
BAPO 0.2 & $92.3(28.6) \mathrm{A}, \mathrm{a}$ & $89.5(3 \mathrm{I} . \mathrm{I}) \mathrm{A}, \mathrm{ab}$ & $101.4(27.6) \mathrm{A}, \mathrm{abc}$ \\
BAPO 0.7 & $90.3(39.2) \mathrm{A}, \mathrm{a}$ & $104.3(25.5) \mathrm{A}, \mathrm{a}$ & $108.5(29.7) \mathrm{A}, \mathrm{ab}$ \\
BAPO I.2 & $95.8(42.6) \mathrm{A}, \mathrm{a}$ & $90.4(32.0) \mathrm{A}, \mathrm{ab}$ & $92.1(35.3) \mathrm{A}, \mathrm{abc}$ \\
BAPO I.7 & $102.8(33.7) \mathrm{AB}, \mathrm{a}$ & $80.0(29.0) \mathrm{B}, \mathrm{ab}$ & $119.7(40.9) \mathrm{A}, \mathrm{a}$ \\
BAPO 2.2 & $88.7(24.9) \mathrm{A}, \mathrm{a}$ & $83.8(47.2) \mathrm{A}, \mathrm{ab}$ & $100.0(28.8) \mathrm{A}, \mathrm{abc}$ \\
\hline
\end{tabular}

Note: Distinct capital letters in a same row and lowercase letters in a same column indicate significant differences $(\rho<0.05)$.

Abbreviations: CQ, camphorquinone; BAPO, bisacylphosphine oxide; DMAEMA, dimethylaminoethyl methacrylate. 
values, regardless of the BAPO concentration. For DMAEMA 0.5 group, BAPO 0.7 showed FS results higher than CQ 0.1 and CQ 3 groups $(\rho<0.05)$, while BAPO 1.7 had FS values higher than CQ 0.1, CQ 0.7, and CQ 0.9 cements for DMAEMA $1.0(\rho<0.05)$.

No statistical differences were found among co-initiator (DMAEMA) groups regardless the type and \%wt of the initiator used, except for all CQ groups in DMAEMA 0 as well as CQ 0.3 and BAPO 1.7 for DMAEMA 0.5 groups that presented the lowest FS values $(\rho<0.05)$.

Table 2 shows the E results. Two-way ANOVA showed a statistically significant interaction between the factors $(\rho=0.001)$, and for initiator $(\rho<0.001)$ and co-initiator $(\rho<0.001)$ tested. For DMAEMA 0 group, the experimental resin cements containing CQ did not polymerize. On the other hand, BAPO 1.7 presented E results higher than BAPO 0.2 $(\rho<0.001)$, whereas the other BAPO groups showed intermediate results without statistical difference $(\rho=0.328)$. The CQ 0.1 group had the lowest $\mathrm{E}$ results for both DMAEMA 0.5 and DMAEMA 1.0 groups $(\rho<0.001)$. The highest $\mathrm{E}$ values were found for BAPO 2.2 (DMAEMA 0.5) and BAPO 1.7 (DMAEMA 1.0) groups $(\rho<0.001)$.

In general, all DMAEMA groups presented statistical similar E values, except for CQ 0.9 and BAPO 1.7 (DMAEMA 0.5) besides all CQ groups (DMAEMA 0) that showed the lowest $\mathrm{E}$ values $(\rho<0.001)$.

\section{Discussion}

The first hypothesis was rejected, since the all experimental resin cements containing CQ without co-initiator (DMAEMA)

Table 2 Means (standard deviations) for elastic modulus (GPa) according to initiator (CQ and BAPO \%wt) and co-initiator (DMAEMA \%wt) used

\begin{tabular}{|c|c|c|c|}
\hline & DMAEMA 0 & DMAEMA 0.5 & DMAEMA I.0 \\
\hline CQ 0.1 & $0.0(0.0) B, c$ & $0.71(0.19) \mathrm{A}, \mathrm{c}$ & $0.76(0.25) \mathrm{A}, \mathrm{c}$ \\
\hline CQ 0.3 & $0.0(0.0) B, c$ & $0.99(0.37) \mathrm{A}, \mathrm{bc}$ & $\mathrm{I} .3 \mathrm{I}(0.60) \mathrm{A}, \mathrm{abc}$ \\
\hline CQ 0.5 & $0.0(0.0) B, c$ & $\mathrm{I} .00(0.49) \mathrm{A}, \mathrm{bc}$ & $\mathrm{I} .33(0.62) \mathrm{A}, \mathrm{abc}$ \\
\hline CQ 0.7 & $0.0(0.0) \mathrm{B}, \mathrm{C}$ & $\mathrm{I} .02(0.46) \mathrm{A}, \mathrm{bc}$ & I.07 (0.85) A,bc \\
\hline CQ 0.9 & $0.0(0.0) C, c$ & $0.96(0.62) \mathrm{B}, \mathrm{bc}$ & $\mathrm{I} .64(0.69) \mathrm{A}, \mathrm{ab}$ \\
\hline BAPO 0.2 & $\mathrm{I} .00(0.44) \mathrm{A}, \mathrm{b}$ & $0.99(0.42) \mathrm{A}, \mathrm{bc}$ & $1.23(0.33) \mathrm{A}, \mathrm{bc}$ \\
\hline BAPO 0.7 & $\mathrm{I} .32(0.64) \mathrm{A}, \mathrm{ab}$ & $\mathrm{I} .4 \mathrm{I}(0.64) \mathrm{A}, \mathrm{ab}$ & $\mathrm{I} .39(0.63) \mathrm{A}, \mathrm{ab}$ \\
\hline BAPO 1.2 & $\mathrm{I} .50(0.49) \mathrm{A}, \mathrm{ab}$ & $1.30(0.49) \mathrm{A}, \mathrm{ab}$ & $\mathrm{I} .30(0.48) \mathrm{A}, \mathrm{abc}$ \\
\hline BAPO 1.7 & $\mathrm{I} .86(0.70) \mathrm{A}, \mathrm{a}$ & $\mathrm{I} .20(0.54) \mathrm{B}, \mathrm{abc}$ & $\mathrm{I} .87(0.83) \mathrm{A}, \mathrm{a}$ \\
\hline BAPO 2.2 & $\mid .31$ (0.33) A,ab & $\mathrm{I} .6 \mathrm{I}(0.70) \mathrm{A}, \mathrm{a}$ & I.65 (0.47) A,ab \\
\hline
\end{tabular}

Note: Distinct capital letters in a same row and lowercase letters in a same column indicate significant differences $(\rho<0.05)$.

Abbreviations: CQ, camphorquinone; BAPO, bisacylphosphine oxide; DMAEMA, dimethylaminoethyl methacrylate. did not polymerize, showing lower FS and $\mathrm{E}$ values than BAPO, corroborating with other studies. ${ }^{14-17}$ The molecular structure of the CQ includes an aromatic group which renders the material photoactive; ${ }^{10,18}$ however, it requires an amine coinitiator to donate hydrogens and generate a free radical capable of initiating polymerization of the material. ${ }^{8} \mathrm{CQ}$ has a half-life to react with the monomers and needs an effective proton donor, since it is a type II photoinitiator. ${ }^{19}$ When a coinitiator was added to the mixture (CQ + DMAEMA), an increase of the FS and $\mathrm{E}$ was observed due to the amine acting as a hydrogen donor that generates free radicals to initiate the polymerization of this system. ${ }^{20}$

The CQ groups containing the co-initiator/amine (DMAEMA 0.5 and DMAEMA 1.0) photopolymerized. This result was in agreement with other studies that evaluated the concentration of initiator/co-initiator and concluded that a 1:2 (CQ/DMAEMA) ratio provided the highest degree of monomer conversion with direct effects on the mechanical and optical properties of the materials. ${ }^{14,17}$ When the amine concentration is lower than that of $\mathrm{CQ}$, spontaneous collision between the co-initiator and initiator becomes more difficult because of the low concentrations of amine in the reaction. In this case, some CQ molecules in the triplet state return to their original singlet state thus reducing the generation of free radicals. ${ }^{8,21-23}$ However, when the amine concentration is higher than that of CQ, the generation of free radicals will depend only on the reactivity of the system, since there will be no collision problems between the CQ and DMAEMA molecules. ${ }^{21,24,25}$

Although the BAPO 1.7 group had shown higher FS and E results in combination with DMAEMA 1.0, this synergism relationship was not verified in other studies. ${ }^{6,26}$ The addition of DMAEMA does not lead to a significant increase in quantum yield or polymerization rate showing that the co-initiator DMAEMA is unnecessary for the BAPO photoinitiator. The discrete increase in mechanical properties could be attributed to the ability of the amine to reduce the inhibition of polymerization caused by oxygen. The oxygen dissolved in the monomer can react with the amine species, forming a peroxide radical which in turn can react with another amine thus releasing a new free radical. ${ }^{27}$

The FS and $\mathrm{E}$ values did not increase according to the concentration of the photoinitiator. Thus, the second hypothesis of this study was rejected. Due to a phenomenon known as the inner shielding effect, high concentrations of the $\mathrm{CQ}$ can behave in a filter-like manner preventing light from reaching deeper portions of the restorations. $^{20,28}$ This is even more crucial when the 
average light penetration at $470 \mathrm{~nm}$ is already considered for conventional dental light-curing units. ${ }^{8,12,13}$

The photoinitiator concentration of a resin-based material must be sufficient to allow a satisfactory polymerization. An inadequate polymerization affects biocompatibility due to the release of unreacted monomers. ${ }^{5,8,25}$ The FS and $\mathrm{E}$ values for different photoinitiators concentrations of the experimental resin cements evaluated could be explained by the fact that they allow the generation of similar amount of free radicals during photoactivation. ${ }^{24}$ The threshold level of photoinitiators concentrations used in this study was selected, since the BisGMA-TEGDMA materials reached the maximum degree of monomer conversion and low yellowing effect. ${ }^{8,11,14,15,17,24,25,29}$ The higher degree of monomer conversion improved the cohesive forces of the polymer network formed in experimental resin cements, which became more rigid to deformation ${ }^{11,13,30}$ improving FS and E values.

The groups containing the BAPO photoinitiator showed the highest values of FS and E, corroborating with other studies. $6,26,31$ The BAPO photoinitiator was able to promote the polymerization alone and thus not requiring the addition of a co-initiator, because after the absorption of light energy, the BAPO molecule undergoes a rupture in the $\mathrm{C}-\mathrm{P}$ bond passing to the triplet state and generating two free radicals. This event can occur twice, having the ability to generate four free radicals per molecule. ${ }^{6,8}$ At room temperature, rupture of the second $\mathrm{C}-\mathrm{P}$ bond is not a spontaneous process and a second photon is needed to break this bond. Thus, there are always two potential radicals $(\mathrm{CH} 3) 3 \mathrm{PhC} \cdot(=\mathrm{O})$ and $(\mathrm{CH} 3) 3 \mathrm{PhC}(=\mathrm{O})-(\mathrm{Ph}) \mathrm{P} \bullet(=\mathrm{O})$ for each absorbed photon. It is known that the first radical is 2-6 times less reactive than the second radical. ${ }^{32}$

BAPO has a much higher molar extinction coefficient $(870 \mathrm{~L} / \mathrm{mol} \mathrm{cm})$ than that of CQ $(33 \mathrm{~L} / \mathrm{mol} \mathrm{cm}) .{ }^{26} \mathrm{In}$ addition, pure BAPO has quantum yield five times higher than CQ. This feature directly reflects the rate of polymerization and the electron flux required for the reaction. The higher the quantum yield, the lower the photon flux required because the reaction requires the least amount of energy to occur. Thus, a three times higher photon energy flux is required for the CQ/DMAEMA system to initiate the reaction when compared to the BAPO or BAPO/DAMEMA system. ${ }^{32,33}$

In addition, the presence of the CQ system in the formulation of the resin materials is related to adverse effects such as cytotoxicity, ${ }^{6}$ yellowing, ${ }^{6,29}$ and reduction of free radical generation when associated with acid monomers. ${ }^{30}$ The emission spectrum of a light source has a strong influence on polymerization performance especially when different photoinitiator systems are compared. BAPO has two light absorption peaks in regions near the ultraviolet, $371 \mathrm{~nm}$ and also $400 \mathrm{~nm}$, although there is also some absorption within the blue range of the visible spectrum. ${ }^{18}$ Unlike CQ, BAPO is activated by smaller wavelengths located in the UV-Vis region. ${ }^{33}$ It is expected that LEDs that emit greater spectrum of light are more effective in the process of polymerization. However, this evidence may be irrelevant in adhesive systems containing light-absorbing photoinitiators in a short wavelength range (400-500 $\mathrm{nm}$ ), e.g. CQ (absorption peak $468 \mathrm{~nm}) .^{21}$ The use of second-generation LEDs improved degree of monomer conversion results for non-BAPO-associated CQ-containing adhesives, whereas third-generation LEDs provided higher degree of monomer conversion to all BAPO adhesive systems. ${ }^{34}$

Additional studies should be conducted in order to approximate the experimental resin cements to a commercially available one, evaluating the inclusion of alternative photoinitiators and the possibility of synergism between them in the monomer composition. The information obtained here has clinical relevance, since they indicate that the manipulation of the concentration of the photoinitiators can significantly increase the mechanical properties of the resin composite.

\section{Disclosure}

The authors declare that they have no conflicts of interest in this work.

\section{References}

1. Xavier TA, Fróes-Salgado NRG, Meier MM, Braga RR. Influence of silane content and filler distribution on chemical-mechanical properties of resin composites. Braz Oral Res. 2015;29:1-8. doi:10.1590/18073107BOR-2015.vol29.0072

2. Aydınoğlu A, Yoruç ABH. Effects of silane-modified fillers on properties of dental composite resin. Mater Sci Eng C Mater Biol Appl. 2017;79:382-389. doi:10.1016/j.msec.2017.04.151

3. Kim KH, Ong JL, Okuno O. The effect of filler loading and morphology on the mechanical properties of contemporary composites. $J$ Prosthet Dent. 2002;87:642-649. doi:10.1067/mpr.2002.125179

4. Ilie N, Hickel R. Resin composite restorative materials. Aust Dent J. 2011;56Suppl 1:59-66. doi:10.1111/j.1834-7819.2010.01296.x

5. Novais VR, Raposo LHA, Miranda RR, Lopes CCA, Simamoto Júnior PC, Soares CJ. Degree of conversion and bond strength of resincements to feldspathic ceramic using different curing modes. J Appl Oral Sci. 2017;25:61-68. doi:10.1590/1678-77572016-0221

6. Albuquerque PPAC, Moreira ADL, Moraes RR, Cavalcante LM, Schneider LF. Colour stability, conversion, water sorption and solubility of dental composites formulated with different photoinitiator systems. $J$ Dent. 2013;41Suppl 3:e67-e72. doi:10.1016/j.jdent.2012.11.020 
7. Chen M, Zhong M, Johnson JA. Light-controlled radical polymerization: mechanisms, methods, and applications. Chem Ver. 2016;116:10167-10211.

8. Meereis CTW, Leal FB, Lima GS, de Carvalho RV, Piva E, Ogliari FA. BAPO as an alternative photoinitiator for the radical polymerization of dental resins. Dent Mater. 2014;30:945-953. doi:10.1016/j. dental.2014.05.020

9. Rueggeberg FA, Ergle JW, Lockwood PE. Effect of photoinitiator level on properties of a light-cured and post-cure heated model resin system. Dent Mater. 1997;13:330-334. doi:10.1016/S0109-5641(97)80107-8

10. Grohmann CVS, Soares EF, Souza-Junior EJC, et al. Influence of different concentration and ratio of a photoinitiator system on the properties of experimental resin composites. Braz Dent J. 2017;28:726-730. doi:10.1590/0103-6440201701372

11. Schneider LFJ, Cavalcante LM, Consani S, Ferracane JL. Effect of coinitiator ratio on the polymer properties of experimental resin composites formulated with camphorquinone and phenyl-propanedione. Dent Mater. 2009;25:369-375. doi:10.1016/j.dental.2008.08.003

12. Leprince JG, Palin WM, Hadis MA, Devaux J, Leloup G. Progress in dimethacrylate-based dental composite technology and curing efficiency. Dent Mater. 2013;29:139-156. doi:10.1016/j.dental.2012.11.005

13. Palin WM, Hadis MA, Leprince JG, et al. Reduced polymerization stress of MAPO-containing resin composites with increased curing speed, degree of conversion and mechanical properties. Dent Mater. 2014;30:507-516. doi:10.1016/j.dental.2014.02.003

14. Schneider LF, Cavalcante LM, Prahl SA, Pfeifer CS, Ferracane JL. Curing efficiency of dental resin composites formulated with camphorquinone or trimethylbenzoyl-diphenyl-phosphine oxide. Dent Mater. 2012;28:392-397. doi:10.1016/j.dental.2011.11.014

15. Alonso RCB, Brandt WC, Souza-Junior EJC, Puppin-Rontani RM, Sinhoreti MAC. Photoinitiator concentration and modulated photoactivation: influence on polymerization characteristics of experimental composites. Appl Adhes Sci. 2014;2:1-11. doi:10.1186/2196-4351-2-10

16. Alonso R, Piveta-Flores FB, Silva MS, et al. Effect on shrinkagestress and degree of conversion. Dent Mater. 2014;30:e82-3. doi:10.1016/j.dental.2014.08.168

17. Schneider LF, Pfeifer CS, Consani S, Prahl SA, Ferracane JL. Influence of photoinitiator type on the rate of polymerization, degree of conversion, hardness and yellowing of dental resin composites. Dent Mater. 2008;24:1169-1177. doi:10.1016/j.dental.2008.01.007

18. Ikemura K, Endo T. A review of the development of radical photopolymerization initiators used for designing light-curing dental adhesives and resin composites. Dent Mater J. 2010;29:481-501.

19. Vaidyanathan TK, Vaidyanathan J, Lizymol PP, Ariya S, Krishnan KV. Study of visible light activated polymerization in BisGMA-TEGDMA monomers with type 1 and type 2 photoinitiators using Raman spectroscopy. Dent Mater. 2017;33:1-11. doi:10.1016/j.dental.2016.09.002

20. Jakubiak J, Allonas X, Fouassier JP, et al. Camphorquinone-amines photoinitating systems for the initiation of free radical polymerization. Polymer. 2003;44:5219-5226. doi:10.1016/S0032-3861(03)00568-8

21. Cook WD. Photopolymerization kinetics of dimethacrylates using the camphorquinone/amine initiator system. Polymer. 1992;33:600-609. doi:10.1016/0032-3861(92)90738-I
22. Di Nunzio MR, Romani A, Favaro G. Excited-state properties of a photochromic spirooxazine: double pathways for both fluorescence emission and camphorquinone-sensitized reaction. J Phys Chem A. 2009;113:9424-9433. doi:10.1021/jp9047743

23. Oguri M, Yoshida Y, Yoshihara K, et al. Effects of functional monomers and photo-initiators on the degree of conversion of a dental adhesive. Acta Biomater. 2012;8:1928-1934. doi:10.1016/j.actbio.2012.01.013

24. Pfeifer CS, Ferracane JL, Sakaguchi RL, Braga RR. Photoinitiator content in restorative composites: influence on degree of conversion, reaction kinetics, volumetric shrinkage and polymerization stress. $\mathrm{Am}$ $J$ Dent. 2009;22:206-210.

25. Ely C, Schneider LF, Ogliari FA, et al. Polymerization kinetics and reactivity of alternative initiators systems for use in light-activated dental resins. Dent Mater. 2012;28:1199-1206. doi:10.1016/j. dental.2012.08.009

26. Neumann MG, Schmitt CC, Horn MA Jr. The effect of the mixtures of photoinitiators in polymerization efficiencies. J Appl Polym Sci. 2009;112:129-134. doi:10.1002/app.v112:1

27. Rueggeberg FA, Margeson DH. The effect of oxygen inhibition on an unfilled/filled composite system. J Dent Res. 1990;69:1652-1658. doi: $10.1177 / 00220345900690100501$

28. Righi H, Costa AR, Oliveira DCRS, Abuna GF, Sinhoreti MAC, Naufel FS. Influence of photoinitiator on accelerated artificial aging and bond strength of experimental resin cements. Braz Dent J. 2018;29:82-87. doi:1590/010/0103-6440201801591

29. Oliveira DC, Souza-Junior EJ, Dobson A, Correr AR, Brandt WC, Sinhoreti MA. Evaluation of phenyl-propanedione on yellowing and chemical-mechanical properties of experimental dental resin-based materials. J Appl Oral Sci. 2016;24:555-560. doi:10.1590/1678775720160058

30. Almeida CM, Meereis CTW, Leal FB, Ogliari AO, Piva E, Ogliari FA. Evaluation of long-term bond strength and selected properties of self-adhesive resin cements. Braz Oral Res. 2018;32:e15. doi:10.1590/1807-3107bor-2018.vol32.0015

31. Brandt WC, Schneider LF, Frollini E, Correr-Sobrinho L, Sinhoreti MA. Effect of different photo-initiators and light curing units on degree of conversion of composites. Braz Oral Res. 2010;24:263-270.

32. Decker C, Zahouily K, Decker D, Nguyen T, Viet T. Performance analysis of acylphosphine oxides in photoinitiated polymerization. Polymer. 2001;42:7551-7560. doi:10.1016/S0032-3861(01)00221-X

33. Neumann MG, Miranda WG Jr, Schmitt CC, Rueggeberg FA, Correa IC. Molar extinction coefficients and the photon absorption efficiency of dental photoinitiators and light curing units. J Dent. 2005;33:525532. doi:10.1016/j.jdent.2004.11.013

34. Oliveira DCRS, Rocha MG, Gatti A, Correr AB, Ferracane JL, Sinhoret MA. Effect of different photoinitiators and reducing agents on cure efficiency and color stability of resin-based composites using different LED wavelengths. J Dent. 2015;43:1565-1572. doi:10.1016/j.jdent.2015.08.015

35. Silami FD, Mundim FM, Garcia LF, Sinhoreti MA, Pires-de-Souza Fde C. Colour stability of experimental composites containing different photoinitiators. J Dent. 2013;41:e62-6. doi:10.1016/j. jdent.2012.10.009

Clinical, Cosmetic and Investigational Dentistry

\section{Dovepress}

\section{Publish your work in this journal}

Clinical, Cosmetic and Investigational Dentistry is an international, peer-reviewed, open access, online journal focusing on the latest clinical and experimental research in dentistry with specific emphasis on cosmetic interventions. Innovative developments in dental materials, techniques and devices that improve outcomes and patient

satisfaction and preference will be highlighted. The manuscript management system is completely online and includes a very quick and fair peer-review system, which is all easy to use. Visit http://www.dovepress.com/testimonials.php to read real quotes from published authors.

Submit your manuscript here: https://www.dovepress.com/clinical-cosmetic-and-investigational-dentistry-journal 